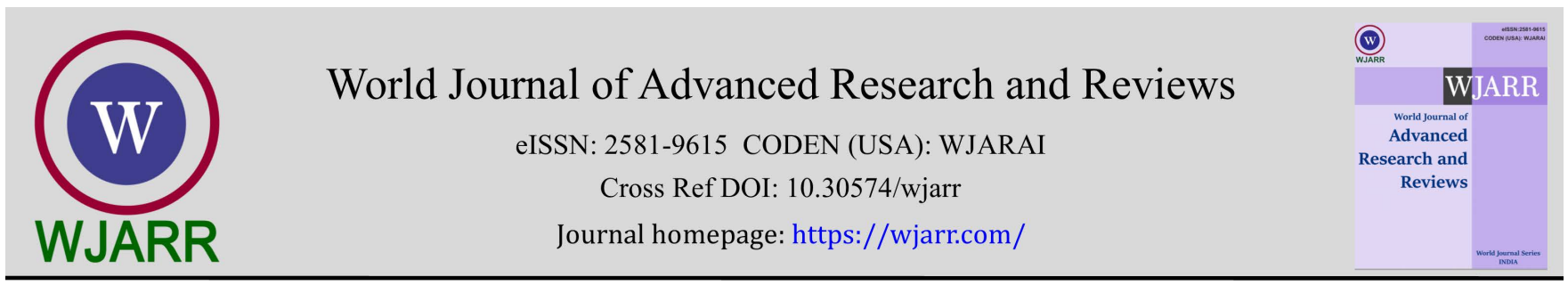

(RESEARCH ARTICLE)

Check for updates

\title{
Frequency of plantar fasciitis due to improper shoes among different universities students
}

\author{
Abdul wahid 1, Muhammad Arsalan Ali Sajid 2, ${ }^{*}$, Ambreen Muzaffar ${ }^{3}$ and Muhammad Zohaib Hussain 4 \\ ${ }^{1}$ Imperial College of Business Studies, Lahore, Pakistan (DPT), (MD)International Medical University, Bishkek, Kyrgyzstan. \\ 2 University of Sargodha, Sargodha, Pakistan) (Pharm-D), (MD)Tashkent Medical Academy, Urgench, Uzbekistan.
}

World Journal of Advanced Research and Reviews, 2021, 12(01), 454-464

Publication history: Received on 06 September 2021; revised on 23 October 2021; accepted on 25 October 2021

Article DOI: https://doi.org/10.30574/wjarr.2021.12.1.0512

\begin{abstract}
Back ground: study was conducted to determine the frequency of plantar fasciitis among three different universities students due to improper shoes. It was cross-sectional study. Plantar fasciitis is the inflammation of plantar fascia; plantar fascia is a thick connective tissue that forms the medial arch of foot. Improper shoes cause constant pressure and irritation on plantar fascia that leads to inflammation. When someone wears improper shoes, pronation activity of the foot decreased and it can lead to plantar fasciitis.
\end{abstract}

Objective: The objective of study was to determine the frequency of plantar fasciitis due to improper shoes among three different universities students.

Material and Methods: Study was cross-sectional and the data was collected from university students. Data was collected by using questionnaire and by applying statistical procedures results were concluded.

Results: There were the following results in this study as, 35.5\% participants without pain, 45\% with mild pain, 16\% with moderate pain and 3.6\% with severe pain. There were $84 \%$ participants with single etiology, $13 \%$ participants with multiple etiology and 3\% participants with nerve entrapment. There were 31 participants with no pain, 49 participants with mild pain, 11 participants with moderate pain and 2 participants with severe pain between ages 20 25 years. And between ages 26-30 there were 29 participants with no pain, 27 with mild pain, 16 with moderate pain and 4 participants with severe pain.

Conclusion: Study concluded that 55.6\% participants were between ages of 20-25 years. 54.4\% participants were females, $59.2 \%$ participants were with no pain, $84 \%$ participants were with single etiology that is plantar fasciopathy.

There were mostly participants suffered with mild pain and only $3.6 \%$ participants showed response with severe pain. There were mostly participants suffered with single etiology and the number of affected participants with plantar fasciitis slightly increased with age.

Keywords: Plantar fasciitis; Improper shoes; Shoe orthoses; Aponeurosis; Palanges; Dorsiflexion

\footnotetext{
${ }^{*}$ Corresponding author: Muhammad Arsalan Ali Sajid

University Of Sargodha, Sargodha, Pakistan(Pharm-D), (MD)Tashkent Medical Academy, Urgench, Uzbekistan. 


\section{Introduction}

\subsection{Definition}

It is the condition characterized with heel pain. The involving structures include the inflammation of thick band in foot, the function of this thick band (plantar fascia) is to connect the heel bone with toes and the inflammation of this band cause heel pain called plantar fascia[1].

Plantar fascia is responsible to maintain the integrity of longitudinal arch of foot. Due to any cause when the plantar fascia becomes irritated, inflamed or goes to torn, it causes heel pain. Causing factors include the excessive pronation of foot, flat foot, Achilles tendon tight, worn training shoes and training routine errors[2].

\subsection{Anatomy of plantar fasciitis}

Anatomical structure of foot contains the tarsal bones, metatarsal bones and phalanges. A broad thick structure between the medial tubercle of calcaneal and the proximal phalanges of the toes is called the plantar fascia. Plantar fascia is also called the aponeurosis. Plantar fascia holds the foot bones at their normal alignment and supports the arches of foot.[3]

\subsection{Foot problems}

Today society people prefer shoes that are stylish, such type of shoes are not comfortable and the size and shape of shoes also not correct. Women like to purchase shoes that are small in size and tight in wearing, women prefer to wear high heels and such type of shoes produce risk factors and many foot disorders that require surgery for recovery. Foot problems include, at the base of big toe enlargement of bone or soft tissue is called bunion. When tight shoes put pressure on the foot skin a type of callus formed which is called corn. Due to improper shoes toes start to curl up instead lying flat, such type of toes called hammer toe. When the shoes are too small a constant pressure is applied on the toes, due to this pressure second or third toe moves over the toe next to it, it is called the crossover toe. Big toe nail grows inward because of tight shoes and when the nail is cut short near the tip of toe, this type of nail is called ingrown toe nail. Among the diabetic patients peripheral neuropathy occurs in the foot. Patients with diabetic foot cannot feel the skin irritations and traumas that lead the blisters or sores that may progress to serious infection[4].

\subsection{Causes of plantar fasciitis}

There are the following causes of plantar fasciitis, worn-out shoes or shoes with thin soles, people having flat feet or a very high arch, shoes with high heels, having heel cord or tight Achilles tendon and unusual walk and abnormal foot position[5].

\subsection{Risk factors}

Some people spend maximum work time on their feet they can be affected by plantar fasciitis. As the ankle dorsiflexion decreases the chances of plantar fasciitis increases. The individuals who have body- mass index $>30 \mathrm{~kg} / \mathrm{m} 2 \mathrm{have}$ increased chance to suffer from plantar fasciitis. Decreased dorsiflexion, obese persons and the work related to weight bearing on feet are the risk factors for plantar fasciitis. Decreased ankle dorsiflexion is the main cause of plantar fasciitis[6].

Among the runners history taken about plantar fasciitis and it showed that plantar fasciitis is also associated with the high loading force, the rate of the loads applied and the lower level of medial arch of foot in runners [7].

To reduce the chance of plantar fasciitis shoe rotation policy can be used. In this procedure shoe orthoses are used with medial longitudinal arch and metatarsal pad for prevention and for treatment strategy. The workers that work on work stations and they attain decrease quantity of time walking or they have to stand on hard surfaces, for example the workers that just attain the sitting and standing position during work and they also spend much time in standing on hard surfaces, among such workers cushioning mats provided to reduce the plantar fasciitis risk factors [8].

\subsection{Treatment}

To treat or prevent the plantar fasciitis, there are many procedures that can be applied. These procedures include strengthening exercises, rest, stretching techniques, arch pads to support the arches, change abnormal shoes with normal and comfortable shoes, use of orthotics, night splints to reduce pain and proper alignment, anti-inflammatory drugs (NSAIDS) and surgical procedures. By reducing risk factors plantar fasciitis can be treated effectively[9]. 


\subsection{Medical treatment}

To treat the acute or chronic plantar fasciitis it has been proved that corticosteroid injection cab be used effectively. In a study of 100 persons having plantar fasciitis treatments were compared as, lidocaine blood injection and (xylocaine) needling, triamcinolone injection and triamcinolone needling, study showed that both triamcinolone groups had better results. There can be possible risk factors due to corticosteroid injection as fat pad atrophy and rupture of plantar fascia of foot. Treatment strategies for plantar fasciitis include modification of activities, ice massage therapy, rest and drugs which include acetaminophen or NSAIDS. A study showed that NSAIDS can be used for plantar fasciitis treatment and relieve pain for short time. Study also showed that there are few studies who show proper results of individual treatment alone for plantar fasciitis.[10]

\subsection{Physical therapy treatment}

Physical therapy treatment for plantar fasciitis includes, stretching exercises to stretch plantar fascia and soleus to increase dorsiflexion, Night splint used for proper ankle and toe alignment. Ankle Foot orthosis used to support the ankle and foot and shoe inserts used that limit the foot pronation and decrease the pressure on plantar fascia. Ice therapy used to reduce pain and inflammation. Iontophoresis application to transport the drug through skin of foot. Taping techniques applied on foot to relieve pain [11].

\subsection{Orthotics}

Plantar fasciitis treatment contains orthotic devices which are made of plastic, rubber and are soft. Arch supports and heel cups decrease pressure on heel during stance phase and works as shock absorbers. A patient with heel pain due to abnormal inward twisting of foot can be relieved by pain with an orthotic device use having an arch support and heel cushion[12].

\section{Literature review}

Robert A, Werner and their colleagues conducted a research program to check the risk factors for plantar fasciitis among plant workers in 2010. Study showed that the workers who stand for long time, suffered from plantar fasciitis. shoe orthosis with medial longitudinal larch and heel cushion pads used to prevent and treat the plantar fasciitis pain [13].

George $\mathrm{H}$, Theodore and colleagues conducted research program on the effectiveness of extracorporeal shock wave therapy for the treatment of plantar fasciitis in 2004. In this study 150 patients selected into two groups with two years of plantar fasciitis history to check extracorporeal shock wave therapy effectiveness. This study showed that ESWT is effective for the treatment of chronic plantar fasciitis[14].

Amit Gefen did research to check the loading on plantar soft tissue among the diabetic patients when they stand in July 2013. In this study different types of load applied on the normal and diabetic foot. Diabetic foot suffered from peripheral neuropathy which cause the decreased sensations and finally lead to traumas. Study showed that among diabetes patients as the foot stiffness increases, the load on medial arch of foot increases and the condition becomes more severe[15].

Sadia Mahmood and her colleagues conducted research to check either limb-length discrepancy is the cause of plantar fasciitis or not in 2010. The study enrolled 26 patients and measurements taken from superior iliac spine to the medial malleolus and from umbilicus to the medial malleolus, and body mass index calculated. Study showed a strong correlation between limb length and unilateral pain [16].

Janise Dennis J and their colleagues did research on shoe modification and use of foot orthotics to treat the ankle and foot problems in 2008. Study showed that foot ankle orthosis can protect from injuries and are the primary prevention. There are different type of shoe modification and orthotics depend upon the problem, working time , comfortability, sports type, and the problems as plantar fasciitis and metatarsalgia[17].

Christopher L. Hendrix did research on calcaneal apophysitis in 2005. Study showed that pain felt at the heel is called calcaneal apophysitis. It occurs among girls at the age of 8-10 years and among boys occurs at the age of 10-12 years. Mostly occurs among the new sportsmen. The cause is the traction force applied at the calcaneus bone where the Achilles tendon attachés, in this condition toe walking reliefs the pain. Symptoms severe by continuing activity or participate in sports for several months [18] 
Kelly murphy and their colleagues conduct research to check either barefoot running reduces injuries among runners or not. The research was conducted in 2013. Research showed that among long distance runners many problems occur as plantar fasciitis, patellofemoral pain syndrome, tibial stress fractures and Achilles tendonitis. Research showed that there should be proper assessment to check the benefits of barefoot running. Although study shows controversy that barefoot running decreases injuries [19].

Stadler, Teresa S and their colleagues conducted research on treatment of plantar fasciitis in 2003.The study showed that the taping techniques, medial arch support and tension type splints are the first choice treatments for plantar fasciitis, if there is no improvement then the extracorporeal shock wave therapy is the recommended treatment option after six months. And when mechanical therapy or ESWT failed to treat the plantar fasciitis after one year, then the last option of treatment is surgery [20].

\section{Objective}

The objective of study was to determine the frequency of plantar fasciitis due to improper shoes among university students.

\section{Rationale}

This study has strong potential to contribute regarding prevention from plantar fasciitis. What so ever the findings come, the study will contribute towards awareness of plantar fasciitis. Awareness regarding shoe shape and type can greatly impact foot health thus saving health related resources by preventing foot problems in general public. This will lead to an important evidence for betterment of community in general.

\section{Material and methods}

\subsection{Study design}

Cross sectional study.

\subsection{Sample size}

- Margin of error: $5 \%$

- Confidence level: $95 \%$

- Population size: 300

- Response distribution: 50\%

- recommended sample size:169

\subsection{Inclusion criteria}

Students of either gender studying medical sciences those willing to participate by signing consent will be included.

\subsection{Exclusion criteria}

Students with known history of trauma or lower limb pathologies that can interfere with weight bearing during walk will be excluded.

\subsection{Data collection tool}

Tool for data collection was questionnaire contains the following parts, Personal information Intensity of pain

Type

Scores $(<12$, plantar fasciitis), (12-15, plantar fasciitis with neurological problems), $(>15$, nerve entrapment)

\subsection{Sample setting}

The region was Imperial University Bahria Town Lahore, International Medical University, Bishkek, Kyrgyzstan, Tashkent Medical Academy, Urgench, Uzbekistan, all sample was collected from students in these areas. 


\subsection{Data Analysis}

After collecting data scores tabulated from an answer key, a frequency analysis carried out on the surveys using SPSS and biostatistics used.

\section{Results}

Results regarding question "Age" there were $55.6 \%$ ( $n=94$ ) with the age 20-25 years and $44.4 \%(n=75)$ with the age of 26-30 years.

Results regarding the question "Gender" there were 45.6\% (n=77) males and 54.4\% ( $\mathrm{n}=92)$ females. Results regarding question "Is your pain worst after periods of rest or with the first step in morning?" there were $59.2 \%$ ( $n=100$ ) with no pain, 33.1\% ( $n=56)$ with rarely pain, $6.5 \%(n=11)$ with sometimes pain and $1.2 \%(n=2)$ said that they have pain. Results regarding question "Does your heel pain increase with the amount of time?" there were39.6 \% (n=67) with no pain, $42.6 \%(n=72)$ with rarely pain, $16.6 \%(n=28)$ with sometimes pain and $1.2 \%(n=2)$ said that they have pain. Results regarding question "does your pain have a burning nature?" there were41.4 \% (n=70) with no pain, 39.6\% (n=67) with rarely pain, $17.2 \%(n=29)$ with sometimes pain and $1.8 \%(n=3)$ answered they have pain.

Results regarding question "do you have heel pain at night or when you are on feet?" there were $36.7 \%$ (n=62) with no pain, $49.1 \%(n=83)$ with rarely pain, $11.2 \%(n=19)$ with sometimes pain and $3.0 \%(n=5)$ answered they have pain.

Results regarding question "Does your pain worsen throughout the day?" there were $36.7 \%$ (n=62) with no pain, $46.2 \%$ $(n=78)$ with rarely pain, $14.2 \%(n=24)$ with sometimes pain and $3 \%(n=5)$ answered they have pain.

Results regarding question "do you have pain in both heels?" there were $34.9 \%$ (n=59) with no pain, 43.2\% (n=73) with rarely pain, $13 \%(n=22)$ with sometimes pain and $8.9 \%(n=15)$ answered they have pain.

Results regarding question "pain intensity" there were $35.5 \%(\mathrm{n}=60)$ participants without pain, $45 \%(\mathrm{n}=76)$ with mild pain, $16 \%(n=27)$ with moderate pain and $3.6 \%(n=6)$ with severe pain.

Table 1 Age

\begin{tabular}{|c|l|c|c|c|c|}
\hline \multicolumn{5}{|c|}{ Age } \\
\hline \multirow{3}{*}{ Valid } & & Frequency & Percent & Valid Percent & Cumulative Percent \\
\cline { 2 - 6 } & $20-25$ Years & 94 & 55.6 & 55.6 & 55.6 \\
\cline { 2 - 6 } & $26-30$ Years & 75 & 44.4 & 44.4 & 100.0 \\
\cline { 2 - 6 } & Total & 169 & 100.0 & 100.0 & \\
\hline
\end{tabular}

Results regarding question "Age" there were 55.6\% (n=94) with the age 20-25 years and 44.4\% (n=75) with the age of 26-30 years.

Table 2 Gender

\begin{tabular}{|c|l|c|c|c|c|}
\hline \multicolumn{5}{|c|}{ Gender } \\
\hline \multirow{2}{*}{ Valid } & & Frequency & Percent & Valid Percent & Cumulative Percent \\
\cline { 2 - 6 } & Fale & 77 & 45.6 & 45.6 & 45.6 \\
\cline { 2 - 6 } & Female & 92 & 54.4 & 54.4 & 100.0 \\
\cline { 2 - 6 } & Total & 169 & 100.0 & 100.0 & \\
\hline
\end{tabular}

Results regarding question "etiology" there were $84 \%(n=142)$ participants with single etiology, 13\% ( $n=22)$ participants with multiple etiology and $3 \%(\mathrm{n}=5)$ participants with nerve entrapment. Results regarding question "Age * Pain intensity? Cross tabulation" there were 31 participants with no pain, 49 participants with mild pain, 11 participants with moderate pain and 2 participants with severe pain between age 20-25 years. And between age 26-30 there were 29 participants with no pain, 27 with mild pain, 16 with moderate pain and 4 participants with severe pain. 
Table 3 Is your pain worst after periods of rest or with the first step in morning?

\begin{tabular}{|c|l|c|c|c|c|}
\hline \multicolumn{5}{|c|}{ Is your pain worst after periods of rest or with the first step in morning? } \\
\hline \multirow{2}{*}{ Valid } & & Frequency & Percent & Valid Percent & Cumulative Percent \\
\cline { 2 - 6 } & No pain & 100 & 59.2 & 59.2 & 59.2 \\
\cline { 2 - 6 } & Rarely & 56 & 33.1 & 33.1 & 92.3 \\
\cline { 2 - 6 } & Sometimes & 11 & 6.5 & 6.5 & 98.8 \\
\cline { 2 - 6 } & Yes & 2 & 1.2 & 1.2 & 100.0 \\
\cline { 2 - 6 } & Total & 169 & 100.0 & 100.0 & \\
\hline
\end{tabular}

Results regarding question "Is your pain worst after periods of rest or with the first step in morning?" there were 59.2\% (n=100) with no pain, $33.1 \%(n=56)$ with rarely pain, $6.5 \%(n=11)$ with sometimes pain and $1.2 \%(n=2)$ said that they have pain.

Table 4 Does your heel pain increase with the amount of time?

\begin{tabular}{|c|l|c|c|c|c|}
\hline \multicolumn{6}{|c|}{ Does your heel pain increase with the amount of time? } \\
\hline \multirow{3}{*}{ Valid } & & Frequency & Percent & Valid Percent & Cumulative Percent \\
\cline { 2 - 6 } & No pain & 67 & 39.6 & 39.6 & 39.6 \\
\cline { 2 - 6 } & Rarely & 72 & 42.6 & 42.6 & 82.2 \\
\cline { 2 - 6 } & Sometimes & 28 & 16.6 & 16.6 & 98.8 \\
\cline { 2 - 6 } & Yes & 2 & 1.2 & 1.2 & 100.0 \\
\cline { 2 - 6 } & Total & 169 & 100.0 & 100.0 & \\
\hline
\end{tabular}

Results regarding question "Does your heel pain increase with the amount of time?" there were39.6 \% (n=67) with no pain, 42.6\% (n=72) with rarely pain, $16.6 \%(n=28)$ with sometimes pain and $1.2 \%(n=2)$ said that they have pain.

Table 5 Does your pain have a burning nature?

\begin{tabular}{|l|l|c|c|c|c|}
\hline \multicolumn{6}{|c|}{ Does your pain have a burning nature? } \\
\hline \multirow{3}{*}{ Valid } & Frequency & Percent & Valid Percent & Cumulative Percent \\
\cline { 2 - 6 } & No pain & 70 & 41.4 & 41.4 & 41.4 \\
\cline { 2 - 6 } & Rarely & 67 & 39.6 & 39.6 & 81.1 \\
\cline { 2 - 6 } & Sometimes & 29 & 17.2 & 17.2 & 98.2 \\
\cline { 2 - 6 } & Yes & 3 & 1.8 & 1.8 & 100.0 \\
\cline { 2 - 6 } & Total & 169 & 100.0 & 100.0 & \\
\hline
\end{tabular}

$41.4 \%(n=70)$ with no pain, $39.6 \%(n=67)$ with rarely pain, $17.2 \%(n=29)$ with sometimes pain and $1.8 \%(n=3)$ answered they have pain.

Table 6 Do you have heel pain at night or when you are on feet?

\begin{tabular}{|l|l|c|c|c|c|}
\hline \multicolumn{5}{|c|}{ Do you have heel pain at night or when you are on feet? } \\
\hline \multirow{3}{*}{ Valid } & & Frequency & Percent & Valid Percent & Cumulative Percent \\
\cline { 2 - 6 } & No pain & 62 & 36.7 & 36.7 & 36.7 \\
\cline { 2 - 6 } & Rarely & 83 & 49.1 & 49.1 & 85.8 \\
\cline { 2 - 6 } & Sometimes & 19 & 11.2 & 11.2 & 97.0 \\
\cline { 2 - 6 } & Yes & 5 & 3.0 & 3.0 & 100.0 \\
\cline { 2 - 6 } & Total & 169 & 100.0 & 100.0 & \\
\hline
\end{tabular}

Results regarding question "do you have heel pain at night or when you are on feet?" there were $36.7 \%$ (n=62) with no pain, $49.1 \%$ (n=83) with rarely pain, $11.2 \%(n=19)$ with sometimes pain and $3.0 \%(n=5)$ answered they have pain. 
Table 7 Does your pain worsen throughout the day?

\begin{tabular}{|l|l|c|c|c|c|}
\hline \multicolumn{6}{|c|}{ Does your pain worsen throughout the day? } \\
\hline \multirow{3}{*}{ Valid } & & Frequency & Percent & Valid Percent & Cumulative Percent \\
\cline { 2 - 6 } & No pain & 62 & 36.7 & 36.7 & 36.7 \\
\cline { 2 - 6 } & Rarely & 78 & 46.2 & 46.2 & 82.8 \\
\cline { 2 - 6 } & Sometimes & 24 & 14.2 & 14.2 & 97.0 \\
\cline { 2 - 6 } & Yes & 5 & 3.0 & 3.0 & 100.0 \\
\cline { 2 - 6 } & Total & 169 & 100.0 & 100.0 & \\
\hline
\end{tabular}

Results regarding question "Does your pain worsen throughout the day?" there were $36.7 \%$ (n=62) with no pain, 46.2\% (n=78) with rarely pain, $14.2 \%(n=24)$ with sometimes pain and $3 \%(n=5)$ answered they have pain.

Table 8 Do you have pain in both heels?

\begin{tabular}{|c|l|c|c|c|c|}
\hline \multicolumn{5}{|c|}{ Do you have pain in both heels? } \\
\hline \multirow{3}{*}{ Valid } & & Frequency & Percent & Valid Percent & Cumulative Percent \\
\cline { 2 - 6 } & No pain & 59 & 34.9 & 34.9 & 34.9 \\
\cline { 2 - 6 } & Rarely & 73 & 43.2 & 43.2 & 78.1 \\
\cline { 2 - 6 } & Sometimes & 22 & 13.0 & 13.0 & 91.1 \\
\cline { 2 - 6 } & Yes & 15 & 8.9 & 8.9 & 100.0 \\
\cline { 2 - 6 } & Total & 169 & 100.0 & 100.0 & \\
\hline
\end{tabular}

Results regarding question "do you have pain in both heels?" there were34.9\% (n=59) with no pain, 43.2\% (n=73) with rarely pain, 13\% (n=22) with sometimes pain and $8.9 \%(\mathrm{n}=15)$ answered they have pain.

Table 9 Does the orthotic device made the heel pain worse?

\begin{tabular}{|l|l|c|c|c|c|}
\hline \multicolumn{5}{|c|}{ Does the orthotic device made the heel pain worse? } \\
\hline \multirow{3}{*}{ Valid } & & Frequency & Percent & Valid Percent & Cumulative Percent \\
\cline { 2 - 6 } & No pain & 82 & 48.5 & 48.5 & 48.5 \\
\cline { 2 - 6 } & Rarely & 70 & 41.4 & 41.4 & 89.9 \\
\cline { 2 - 6 } & Sometimes & 17 & 10.1 & 10.1 & 100.0 \\
\cline { 2 - 6 } & Total & 169 & 100.0 & 100.0 & \\
\hline
\end{tabular}

Results regarding question "does the orthotic device made the heel pain worse?" there were $48.5 \%$ (n=82) with no pain, $41.4 \%$ (n=70) with rarely pain and $10.1 \%(n=17)$ with sometimes pain.

Table 10 Pain intensity?

\begin{tabular}{|c|l|c|c|c|c|}
\hline \multicolumn{5}{|c|}{ Pain intensity? } \\
\hline \multirow{3}{*}{ Valid } & Frequency & Percent & Valid Percent & Cumulative Percent \\
\cline { 2 - 6 } & No pain & 60 & 35.5 & 35.5 & 35.5 \\
\cline { 2 - 6 } & Mild pain (1-3points) & 76 & 45.0 & 45.0 & 80.5 \\
\cline { 2 - 6 } & Moderate pain (4-6points) & 27 & 16.0 & 16.0 & 96.4 \\
\cline { 2 - 6 } & Severe pain (7-10points) & 6 & 3.6 & 3.6 & 100.0 \\
\cline { 2 - 6 } & Total & 169 & 100.0 & 100.0 & \\
\hline
\end{tabular}

Results regarding question "pain intensity" there were $35.5 \%(\mathrm{n}=60)$ participants without pain, $45 \%(\mathrm{n}=76)$ with mild pain, 16\% (n=27) with moderate pain and $3.6 \%(n=6)$ with severe pain. 
Table 11 Etiology?

\begin{tabular}{|l|l|c|c|c|c|}
\hline \multicolumn{5}{|c|}{ Etiology? } \\
\hline \multirow{3}{*}{ Valid } & Single Etiology & 142 & 84.0 & 84.0 & 84.0 \\
\cline { 2 - 6 } & Multiple etiology & 22 & 13.0 & 13.0 & 97.0 \\
\cline { 2 - 6 } & Nerve entrapment & 5 & 3.0 & 3.0 & 100.0 \\
\cline { 2 - 6 } & Total & 169 & 100.0 & 100.0 & \\
\hline
\end{tabular}

Results regarding question "etiology" there were 84\% (n=142) participants with single etiology, 13\% (n=22) participants with multiple etiology and $3 \%(n=5)$ participants with nerve entrapment.

Table 12 Age * Pain intensity? Cross tabulation

\begin{tabular}{|c|c|c|c|c|c|c|}
\hline \multicolumn{7}{|c|}{ Age * Pain intensity? Cross tabulation } \\
\hline \multicolumn{7}{|c|}{ Count } \\
\hline & & \multicolumn{4}{|c|}{ Pain intensity? } & \multirow[t]{2}{*}{ Total } \\
\hline & & No pain & $\begin{array}{l}\text { Mild pain } \\
\text { (1-3points) }\end{array}$ & $\begin{array}{c}\text { Moderate pain } \\
\text { (4-6points) }\end{array}$ & $\begin{array}{c}\text { Severe pain } \\
\text { (7-10points) }\end{array}$ & \\
\hline \multirow[t]{2}{*}{ Age } & 20-25 Years & 31 & 49 & 11 & 2 & 93 \\
\hline & 26-30 Years & 29 & 27 & 16 & 4 & 76 \\
\hline \multicolumn{2}{|c|}{ Total } & 60 & 76 & 27 & 6 & 169 \\
\hline
\end{tabular}

Results regarding question "Age * Pain intensity? Cross tabulation" there were 31 participants with no pain, 49 participants with mild pain, 11 participants with moderate pain and 2 participants with severe pain between age 20-25 years. And between age 26-30 there were 29 participants with no pain, 27 with mild pain, 16 with moderate pain and 4 participants with severe pain.

\begin{tabular}{|l|c|c|c|}
\hline \multicolumn{4}{|c|}{ Chi-Square Tests } \\
\hline & Value & Df & Asymp. Sig. (2-sided) \\
\hline Pearson Chi-Square & $6.382^{\mathrm{a}}$ & 3 & .094 \\
\hline Likelihood Ratio & 6.425 & 3 & .093 \\
\hline Linear-by-Linear Association & .732 & 1 & .392 \\
\hline N of Valid Cases & 169 & & \\
\hline \multicolumn{1}{|c|}{ a. 2 cells (25.0\%) have expected count less than 5. The minimum expected count is 2.70. }
\end{tabular}

Table 13 Gender* Etiology? Cross tabulation

\begin{tabular}{|l|l|c|c|c|c|}
\hline \multicolumn{5}{|c|}{ Gender * Etiology? Cross tabulation } \\
\hline & & \multicolumn{3}{|c|}{ Count } & Etiology? \\
\hline & & Single Etiology & Multiple etiology & Nerve entrapment & \\
\hline \multirow{2}{*}{ Gender } & Male & 72 & 5 & 0 & 77 \\
\cline { 2 - 5 } & Female & 70 & 17 & 5 & 92 \\
\hline Total & 142 & 22 & 5 & 169 \\
\hline
\end{tabular}


Table 14 Chi- Square Tests of Ratios

\begin{tabular}{|c|c|c|c|}
\hline \multicolumn{4}{|l|}{ Chi-Square Tests } \\
\hline & Value & Df & Asymp. Sig. (2-sided) \\
\hline Pearson Chi-Square & $10.324^{\mathrm{a}}$ & 2 & .006 \\
\hline Likelihood Ratio & 12.543 & 2 & .002 \\
\hline Linear-by-Linear Association & 10.234 & 1 & .001 \\
\hline N of Valid Cases & 169 & & \\
\hline
\end{tabular}

Results regarding question "Gender* Etiology? Cross tabulation" there were 72 with single etiology and 5 with multiple etiology male participants. There were 70 with single etiology, 17 with multiple etiology and 5 with nerve entrapment female participants

\section{Discussion}

The conducted study was cross-sectional study to determine the frequency of plantar fasciitis among university students. In plantar fasciitis pain felt at inferior heel region and because of heel pain an individual cannot perform their daily activities or performs in an abnormal way and the exact cause of plantar fasciitis not clearly understood and it probably contains multiple causes.

There can be the following causes as decreased dorsiflexion, overweight, anatomical variations, overexertion, poor biomechanics and wearing abnormal shoes, this research study basically conducted to find the frequency of plantar fasciitis due to wearing abnormal shoes. By taking history study showed that plantar fasciitis can take months to years to resolve depending on the severity and it has become a challenge for clinicians to diagnose and treat.

When we take a look on foot anatomy studies concluded that it is the inflammation of plantar fascia. Plantar fasciitis is the degenerative syndrome caused by repeated trauma on plantar fascia, plantar fascia is the thick connective tissue that originates from the medial tubercle of calcaneus bone and fans out to attach with the plantar plates to form medial longitudinal arch.

Study showed that when an individual wears abnormal shoes continuous pressure on the plantar fascia cause trauma that finally leads to pain. During walk when we step forward , as the leg raises tibia rotates inward and pronation on foot stretch the plantar fascia, but due to abnormal shoes pronation on foot decreased and is also the risk factor for trauma.

Heel spurs have commonly been implicated as a risk factor for PF.

The classic presentation of PF is pain on the sole of the foot at the inferior region of the heel. Participants complained the pain to become severe with the first few steps taken on rising in the morning.

Diagnosis of PF is usually made on the basis of history and physical examination. Pain on first rising in the morning is typical of PF and may be helpful in distinguishing it from other forms of heel pain. For example, in the case of a calcaneal stress fracture or nerve entrapment, pain would actually increase with more walking, rather than diminished after the first few steps and associated paresthesia is not a common characteristic of PF.

In this study by taking history and on the basis of results it was concluded that there is lack of awareness related to plantar fasciitis, mostly students just preferred the shoes because they were beautiful a small number of students were founded that bought shoes by quality and comfortable.

Regarding results showed that although there were small number of students that were affected with plantar fasciitis but there were the majority that showed no awareness about plantar fasciitis, its treatment options and preventive strategies. 


\section{Conclusion}

Study concluded that mostly participants were between ages of 20-25 years, there were mostly females and great number of participants showed negative response to pain, $84 \%$ participants were with single etiology that is plantar fasciopathy. There were mostly participants suffered with mild pain and only a few participants showed response with severe pain. There were mostly participants suffered with single etiology and the number of affected participants with plantar fasciitis slightly increased with age.

\section{Recommendations}

Recommendations included that there should be awareness among students related to plantar fasciitis treatment and preventive strategies. There should be awareness to students that by wearing comfortable shoes and adopting good walk pattern, plantar fasciitis chances can be minimized.

For awareness there should be workshops and seminars conducted by physiotherapists and their focus should be on foot problems due to abnormal shoes.

\section{Compliance with ethical standards}

\section{Acknowledgments}

The completion of this research article could not have been possible without the participation and assistant of following people, we all research members like to express their deep appreciation and indebtedness to following:

Dr Muhammad Hassan, Dr Wasif Hashmi, Dr zayoda Aktamova, Dr Madina Barbekova for their endless support, kind and understanding support.

Above all, to the Great Almighty, the author of knowledge and wisdom, for his countless love.

We thank you.

\section{Disclosure of conflict of interest}

Abdul wahid, Muhammad Arsalan Ali Sajid, Ambreen Muzaffar and Muhammad Zohaib Hassan declare that they have no conflict of interest.

\section{Statement of informed consent}

The consents were taken from all the participants included in this study.

\section{References}

[1] Benjamin K. Buchanan; Donald Kushner. plantar-fasciitis 2018 [updated March 07, 2018; cited 201826 april].

[2] B L Warren. Plantar Fasciitis in Runners Treatment and Prevention. 1990; 10(5).

[3] Wikipedia tfe. Plantar fascia: wikipedia; 2018 [cited 201826 april].

[4] Stuart J. Fischer M, Steven L. Haddad M. Tight Shoes and Foot Problems: otho info; august 2012 [cited 201826 april].

[5] Sabrina Felson M. Plantar Fasciitis: Symptoms, Causes, and Treatment 2017 [cited 201826 april].

[6] Riddle DL, Pulisic M, Pidcoe P, Johnson RE. Risk factors for plantar fasciitis: a matched case-control study. JBJS. 2003; 85(5): 872-7.

[7] Pohl MB, Hamill J, Davis IS. Biomechanical and anatomic factors associated with a history of plantar fasciitis in female runners. Clinical Journal of Sport Medicine. 2009; 19(5): 372-6.

[8] Werner RA, Gell N, Hartigan A, Wiggerman N, Keyserling WM. Risk factors for plantar fasciitis among assembly plant workers. Pm\&r. 2010; 2(2): 110-6. 
[9] Young CC, Rutherford DS, Niedfeldt MW. Treatment of plantar fasciitis. American family physician. 2001; 63(3): 467-74, 77-8.

[10] JAMES D. GOFF D. Diagnosis and Treatment of Plantar Fasciitis. 2011.

[11] Shaw Bronner P, PhD, OCS. How Can a Physical Therapist Help? : APTA move farward; 2011 [updated November 28, 2011; cited 201826 april].

[12] med w. Shoe Inserts for Plantar Fasciitis - Topic Overview 2005 - 2018 WebMD [cited 201826 april].

[13] colleagues RAwa. Risk Factors for Plantar Fasciitis Among Assembly Plant Workers. 2010.

[14] Jeorge H tac. Extracorporeal Shock Wave Therapy for the Treatment of Plantar Fasciitis. 2004.

[15] Gefen A. Plantar soft tissue loading under the medial metatarsals in the standing diabetic foot. 2003.

[16] Mahmood S, Huffman LK, Harris JG. Limb-length discrepancy as a cause of plantar fasciitis. Journal of the American Podiatric Medical Association. 2010; 100(6): 452-5.

[17] Jenisse DJac. Shoe Modification and the Use of Orthoses in the Treatment of Foot and Ankle Pathology. $2008 ; 16$.

[18] hendrix CL. Calcaneal apophysitis (Sever disease). 2005; 22.

[19] Kelly Murphy, Emily J Curry, Elizabeth G Matzkin. Barefoot Running: Does It Prevent Injuries? $2013 ; 43$.

[20] Stadler TS, Johnson ED. What is the best treatment for plantar fasciitis? Clinical Inquiries, 2003 (MU). 2003.

\section{Appendix I}

\section{Questionnaire}

- Age

- Gender

\begin{tabular}{|l|c|}
\hline $\mathbf{0}=$ no; $\mathbf{1}=$ Rarely; $\mathbf{2}=$ Some times; $\mathbf{3}=$ Yes & \\
\hline $\begin{array}{l}\text { Is your pain worst after periods of rest or with the first step in the } \\
\text { morning? }\end{array}$ & 0123 \\
\hline $\begin{array}{l}\text { Does your heel pain increase in relation to the amount of time you are on } \\
\text { your feet? }\end{array}$ & 0123 \\
\hline Does your pain have a burning nature? & 0123 \\
\hline Do you have pain in your heel(s) at night or when you are not on your feet? & 0123 \\
\hline Does your pain worsen throughout the day? & 0123 \\
\hline Do you have pain in both heels? & 0123 \\
\hline $\begin{array}{l}\text { Add three points if prior treatment with orthotic devices made the heel } \\
\text { pain worse? }\end{array}$ & 0123 \\
\hline
\end{tabular}

\begin{tabular}{|c|c|}
\hline $\begin{array}{l}\text { Pain intensity } \\
\text { (NPRS) }\end{array}$ & 0 =no pain5 = moderate pain ; 10 = severe pain \\
\hline Total & SCORING \\
\hline$<12$ points & Most likely a single etiology plantar fasciopathy. \\
\hline $12-15$ points & Probably multiple etiologies both fasciopathy and neurogenic etiology. \\
\hline$>15$ points & $\begin{array}{l}\text { Nerve entrapment or neurogenic etiology is likely the most significant } \\
\text { contributor. }\end{array}$ \\
\hline
\end{tabular}

https://www.google.com.pk/search?biw=1280\&bih=694\&tbm=isch\&sa=1\&ei=I5zlWr7QBuLE6ASUiZeoBw\&q=planta $\mathrm{r}+$ fasciitis++questionnaire\&oq=plantar+fasciitis++questionnaire\&gs_l=psy- 